\title{
Trihoney improves testicular weight change and histopathological alterations in hypercholesterolemic rabbits
}

\author{
Zenab B. Hamad Mohamed ${ }^{a^{*}}$, Hamad Abdulsalam Hamad Alfarisia, Azantee Yazmie Abdul Wahab ${ }^{\mathrm{b}}$, \\ Azliana binti Abd Fuaat ${ }^{\mathrm{c}}$, Che Anuar Che Mohamad ${ }^{\mathrm{d}}$, Muhammad Bin Ibrahim ${ }^{\mathrm{e}}$ \\ ${ }^{a}$ Department of Nutrition Sciences, Kulliyyah of Allied Health Sciences, International Islamic University Malaysia, 25200 Kuantan, Pahang, \\ Malaysia \\ ${ }^{b}$ Department of Obstetrics and Gynaecology, Kulliyyah of Medicine, International Islamic University Malaysia, 25200 Kuantan, Pahang, \\ Malaysia \\ 'Department of Pathology \& Laboratory Medicine, International Islamic University Malaysia Medical Centre, 25200 Kuantan, Pahang, \\ Malaysia \\ ${ }^{d}$ Department of Basic Medical Sciences, Kulliyyah of Pharmacy, International Islamic University Malaysia, 25200 Kuantan, Pahang, Malaysia \\ ${ }^{\circ}$ Central Research \& Animal Facility (CRE AM), Kulliyyah of Science, International Islamic University Malaysia, 25200 Kuantan, Pahang, \\ Malaysia
}

Received 28th March 2020 / Accepted 4th July 2020

\begin{abstract}
Histopathological examination of testicular tissue is the most reliable and sensitive method for detecting effects on spermatogenesis. Hypercholesterolemia reduces testicular weight, induces testicular degenerative changes, impairs spermatogenesis, affects Leydig and Sertoli cells and induces inflammation and fibrosis of testicular tissue. Based on numerous studies, honey has the ability to improve testicular histopathological abnormalities. To date, whether honey has any protective role against the effects of hypercholesterolemia on male reproductive functions is yet to be explored. This study investigated the effects of Trihoney (a mixture of Trigona, Mellifera and Tualang honeys) on changes in testicular weight and histopathological alterations induced by hypercholesterolemia in male New Zealand white rabbits. These changes were compared with the effects of atorvastatin (a lipid lowering agent) based on the same parameters. Forty-eight male New Zealand white rabbits were assigned into 6 groups and received different diets as follows; Control: commercial pellet; $\mathrm{CH}$ : commercial pellet and $0.6 \mathrm{~g} / \mathrm{kg} / \mathrm{day}$ Trihoney; HCD: $1 \%$ cholesterol diet; DH1: $1 \%$ cholesterol diet and $0.3 \mathrm{~g} / \mathrm{kg} /$ day Trihoney; DH2: $1 \%$ cholesterol diet and $0.6 \mathrm{~g} / \mathrm{kg} /$ day Trihoney; DAt: $1 \%$ cholesterol diet and $2 \mathrm{mg} / \mathrm{kg} /$ day atorvastatin. After 12 weeks, blood samples were collected for lipid analysis, the rabbits were sacrificed and the testes were harvested to evaluate any weight and histopathological changes. Administration of $1 \%$ cholesterol diet either alone or in combination with atorvastatin caused a significant reduction in the testicular weight, testicular tubular degenerative changes and spermatogenesis impairment. Trihoney, particularly, at the dose of $0.6 \mathrm{~g} / \mathrm{kg} / \mathrm{day}$ improved testicular weight, ameliorated the testicular tubular degenerative changes and enhanced spermatogenesis. The findings of this study suggest that Trihoney plays a favourable role in the protection against testicular weight reduction and histopathological changes induced by hypercholesterolemia. On the other hand, atorvastatin per se may have toxic effects on testicular tissue.
\end{abstract}

Keywords: Atorvastatin, histology, hypercholesterolemia, organ weight, testes, Trihoney

\footnotetext{
*Authors for correspondence: Muhammad Bin Ibrahim, Central Research \& Animal Facility (CREAM), Kuliyyah of Science, International Islamic University Malaysia, 25200 Kuantan, Pahang, Malaysia. Email abumaisarah@iium.edu.my; Zenab B. Hamad Mohamed, Department of Nutrition Sciences, Kuliyyah of Allied Health Sciences, International Islamic University Malaysia, 25200 Kuantan, Pahang, Malaysia. Email zenab.B.zoubi@gmail.com
} 


\section{INTRODUCTION}

Testicular tissue consists of two functionally and structurally distinct parts. The first part is composed of seminiferous tubules that constitute $80 \%$ of the mass of testis. It is the site where spermatogenesis takes place. The second part contains Leydig or interstitial cells which are located between the seminiferous tubules. It is the site of testosterone production (Sherwood, 2010). It is believed that the histopathological examination of testicular tissue is the most reliable and sensitive method for detecting the effects on spermatogenesis (Vidal \& Whitney, 2014). Organ weight is another sensitive parameter for detection of function and content of the organs (Creasy, 2001). As the growth and maintenance of testes are not affected by body weight changes, the absolute weight of testes should be used rather than the relative (Creasy \& Chapin, 2013). A grown body of evidence has linked hypercholesterolemia with weight changes and histopathological alterations of male reproductive organs. Hypercholesterolemia reduces testicular weight, induces testicular degenerative changes, impairs spermatogenesis (Ashrafi et al., 2013; Shalaby, 2004), affects Leydig and Sertoli cells (Bataineh \& Nusier, 2005; Zhang et al., 2012) and induces inflammation and fibrosis of testicular tissue (Al-Kushi et al., 2016). On the other hand, honey exhibited its ability to improve testicular histopathological abnormalities in numerous experimental studies. It attenuated the impacts of various diseases and toxicants such as diabetes (Michael et al., 2015), cigarette smoke (Mohamed et al., 2011) and noise stress (Saki et al., 2013) on testicular tissue. Trihoney is a mixture of three types of honey namely Trigona, Mellifera and Tualang at a specific ratio. It is a product developed by the Department of Nutrition Sciences, Kulliyyah of Allied Health Sciences, International Islamic University Malaysia (IIUM). It was optimized using Response Surface Methodology (RSM) of Design Expert Version 6.0 software. It is characterized by the high total phenolic content (TPC). The phenolic components that have been characterized in Trihoney include: Quercetin, Kaempferol, Rutin, Catechin, Maleic acid, Caffeic acid, Cinnamic acid, Coumaric acid, Gallic acid, p-Hydroxybenzoic acid, Salicylic acid, Sinapic acid, Vanillic acid. This study is a continuation of our recently published study that investigated the ameliorative effects of Trihoney on hypercholesterolemia-induced epididymal weight and histopathological changes. Trihoney showed its protective effects against epididymal weight reduction and histopathological alterations in hypercholesterolemic male rabbits (Mohamed et al., 2020). To date, whether honey has any protective role against the effects of highcholesterol diet and hypercholesterolemia on testicular tissue is yet to be explored. Herein, this study aims to investigate the effects of Trihoney on testicular weight changes and histopathological alterations induced by hypercholesterolemia in male rabbits and compare its effects with atorvastatin. Atorvastatin is most commonly used among statins, which considered to be the most important class of lipid lowering agents (Jasińska et al., 2007; Pons-Rejraji et al., 2014).

\section{MATERIALS AND METHODS}

\section{Ethics statement}

The details of the animal studies described herein were reviewed and approved by the International Islamic University Malaysia Institutional Animal Care and Use Committee (IACUC-IIUM), IIUM, Kuantan campus (No. of IACUC Approval: IIUM/IACUC Approval/2017/(18)-2, and are conformed to the guidelines for the Malaysian Code of Practice for the Care and Use of Animal for Scientific Purposes.

\section{Chemicals}

Atorvastatin (Atorvastatin Winthrop ${ }^{\circledR}$, PragueCzech), cholesterol powder (Nacalai-Tesque, Japan), cholesterol-free extra virgin coconut oil (Certified Organic, Philippines), Bouin's fixative fluid (Labchem Sdn Bhd, Malaysia), Haematoxylin and Eosin stain (Leica, Germany) and Masson's Trichrome stain (Clin-Tech Limited, UK).

\section{Animals and diets}

A total of 48 mature male New Zealand white rabbits with a body weight of 2000-2500 g were 
used in this study. The sample size was calculated by power and sample size calculation (PS) software program version 3.1.2. The rabbits were housed separately in cages at a temperature of 15$21^{\circ} \mathrm{C}$ and humidity of $45-65 \%$ with 12 hours light/dark cycles. All rabbits had free access to water and commercial pellet for an acclimatization period of 2 weeks before starting the experiment. The rabbits were, thereafter, randomly divided into one of six groups of eight animals, each was as follows:

Group 1: Control (C) (Commercial rabbit pellet). Group 2: $\mathrm{CH}$ (Commercial rabbit pellet with a daily oral dose of $0.6 \mathrm{~g} / \mathrm{kg} /$ day Trihoney).

Group 3: HCD (1\% cholesterol diet; 10 grams of cholesterol powder with $20 \mathrm{~mL}(2 \%)$ of cholesterol-free extra virgin coconut oil and 970 grams of commercial rabbit pellet).

Group 4: DAt (1\% cholesterol diet and a daily oral dose of $2 \mathrm{mg} / \mathrm{kg} /$ day atorvastatin).

Group 5: DH1 (1\% cholesterol diet and a daily oral dose of $0.3 \mathrm{~g} / \mathrm{kg} /$ day Trihoney).

Group 6: DH2 (1\% cholesterol diet and a daily oral dose of $0.6 \mathrm{~g} / \mathrm{kg} /$ day Trihoney).

Trihoney dose was calculated based on the conversion of human equivalent dose to animal equivalent dose according to the equation of Reagan-Shaw et al. (2007):

\section{Human equivalent dose $\times$ Human $K_{m}$ factor $=$ Animal equivalent dose $\times$ Animal $K_{m}$ factor}

Where $\mathrm{K}_{\text {m }}$ factor is a constant value calculated based on the body surface area. Body surface areabased dose calculation is the most appropriate method and is far superior to the simple conversion based on body weight (Reagan-Shaw et al., 2007).

The used dose of atorvastatin was 2 $\mathrm{mg} / \mathrm{kg} /$ day based on a previously conducted study that used the same dose of atorvastatin treatment in hypercholesterolemic male New Zealand white rabbit model (Du et al., 2013). It was reconstituted in $1 \mathrm{~mL}$ of distilled water, then was administered orally (Song et al., 2014). The whole duration of the experiment was 12 weeks. At the end of the experiment, all the rabbits were humanely sacrificed. Animal sacrificing was performed at Central Research and Animal
Facility (CREAM), IIUM, Malaysia. The rabbits fasted overnight and euthanized using intramuscular injection of ketamine/xylazine at a dose of $50 / 10 \mathrm{mg} / \mathrm{kg}$ body weight (Zhao et al., 2013) followed by exsanguination (Leary et al., 2013). Blood samples were collected from all rabbits for analysis of lipid profile using the automated analysis machine (Au480 Au AnalyserBeckman Coulter, Inc.). A longitudinal incision was made through the abdominal cavity and pelvis to expose the internal organs. The testes and epididymides were carefully excised, rinsed with normal saline, separated from each other and weighed (Galaly et al., 2014). One testis from each rabbit was transversely cut into two halves and fixed in Bouin's fixative (Creasy et al., 2008).

\section{Histological examination}

The fixed testes were processed and embedded in paraffin blocks. The blocks were then sectioned transversely into $4 \mu \mathrm{m}$ thickness. The sections were subsequently stained with haematoxylin and eosin stain (H\&E) and Masson's Trichrome stain. The slides were evaluated histologically using a light microscope (Leica, Germany) and were analysed for the microscopic features. The slides were scanned using Leica Aperio CS2 digital scanner. Photographs of the microscopic features were captured using Aperio ImageScope from Leica Biosystem version 12.4.0.5043.

\section{Histological measurements}

The measurement of tunica albuginea thickness of each testis was performed in 4 different regions; the average was calculated and taken as the thickness of tunica albuginea. Diameters measurements of 60 random rounded seminiferous tubules from each testis were also calculated (Mohamed et al., 2012). All measurements were calculated using Aperio ImageScope from Leica Biosystem version 12.4.0.5043.

\section{Spermatogenesis evaluation}

Spermatogenesis process was evaluated in 60 seminiferous tubules from each testis using modified Johnsen's scoring as illustrated in Table 1 (Erdemir et al., 2012). Johnsen's score is a histopathological score used for evaluation of sperm maturation in the seminiferous tubules of the testes (Dohle et al., 2012). 
Table 1. Modified Johnsen's score.

\begin{tabular}{clc}
\hline Score & \multicolumn{1}{c}{ Histopathology } \\
\hline 10 & Full spermatogenesis. \\
\hline 9 & $\begin{array}{l}\text { Slightly impaired spermatogenesis, many late } \\
\text { spermatids and disorganized epithelium. }\end{array}$ \\
\hline 8 & $\begin{array}{l}\text { Less than five spermatozoa per tubule, few late } \\
\text { spermatids. }\end{array}$ \\
\hline 7 & $\begin{array}{l}\text { No spermatozoa, no late spermatids and many } \\
\text { early spermatids. }\end{array}$ \\
\hline 6 & $\begin{array}{l}\text { No spermatozoa, no late spermatids and few } \\
\text { early spermatids. }\end{array}$ \\
\hline 5 & $\begin{array}{l}\text { No spermatozoa or spermatids, many } \\
\text { spermatocytes. }\end{array}$ \\
\hline 4 & $\begin{array}{l}\text { No spermatozoa or spermatids, few } \\
\text { spermatocytes. }\end{array}$ \\
\hline 3 & Spermatogonia only. \\
\hline 2 & No germinal cells, Sertoli cells only. \\
\hline 1 & No seminiferous epithelium. \\
\hline
\end{tabular}

\section{Statistical analysis}

Statistical Package for the Social Sciences Version 21 (SPSS Inc., Chicago, Illinois, USA) was used to perform the statistical analysis. The data were expressed as means and standard deviations. All variables were normally distributed. One-way analysis of variance test (ANOVA) was used for the data analysis followed by a post hoc test to determine the significant differences between the means of the independent groups. Differences were considered to be statistically significant at $p<0.05$ and $p<0.01$. The relationships among the analysed parameters were investigated using Pearson's correlation coefficients. $P$ value $<0.01$ was considered statistically significant.

\section{RESULTS}

\section{The effects of hypercholesterolemia, Trihoney and atorvastatin on serum total cholesterol and low-density lipoprotein cholesterol}

The results of serum total cholesterol (TC) and low-density lipoprotein cholesterol (LDL-c) after 12 weeks of $1 \%$ cholesterol diet, Trihoney and atorvastatin administration are given in Table 2 . There was no significant difference between the $\mathrm{CH}$ group and the control group in the serum TC and LDL-c $(p>0.05)$. Feeding of rabbits with 1\% cholesterol diet markedly increased serum TC and LDL-c levels in the HCD group $(p<0.01)$, Trihoney received groups $(p<0.01)$ and DAt group $(p<0.01)$ compared to the control group. Treatment of rabbits with atorvastatin significantly reduced serum TC $(p<0.05)$ and LDL-c $(p<0.05)$ when compared to the HCD group. Trihoney received groups expressed significantly lower levels of serum TC than the high cholesterol diet group $(p<0.01)$. Compared to the high cholesterol diet group, the reduction in serum LDL-c was more evident in DH2 $(p<0.01)$ than DH1 $(p<0.05)$. No significant difference was detected among Trihoney received groups and atorvastatin treated group in serum TC or LDL-c levels $(p>0.05)$.

Table 2. The effects of $1 \%$ cholesterol diet, Trihoney and atorvastatin on serum total cholesterol and lowdensity lipoprotein cholesterol after 12 weeks.

\begin{tabular}{|c|c|c|c|c|c|c|}
\hline Groups & $\mathrm{C}$ & $\mathrm{CH}$ & HCD & DAt & DH1 & DH2 \\
\hline Lipids & & & & & & \\
\hline $\begin{array}{c}\text { TC } \\
(\mathrm{mmol} / \mathrm{L})\end{array}$ & $0.48 \pm 0.72$ & $1.13 \pm 0.78$ & $46.19 \pm 5.67^{* *}$ & $37.35 \pm 2.36^{* *}, \#$ & $35.44 \pm 4.21^{* *, \# \#}$ & $35.45 \pm 5.98^{* *}, \# \#$ \\
\hline $\begin{array}{c}\text { LDL-c } \\
(\mathrm{mmol} / \mathrm{L})\end{array}$ & $0.14 \pm 0.34$ & $0.41 \pm 0.65$ & $37.60 \pm 6.88^{* *}$ & $27.17 \pm 6.39^{* *}, \#$ & $26.48 \pm 5.53^{* *}, \#$ & $23.11 \pm 8.26^{* *, \# \#}$ \\
\hline
\end{tabular}

Data were analysed using one-way analysis of variance (ANOVA). A Post Hoc comparison using Tukey HSD test was used to test the significant difference between the groups. Values are given as mean \pm standard deviation. ${ }^{* *}$ : significantly different from the control

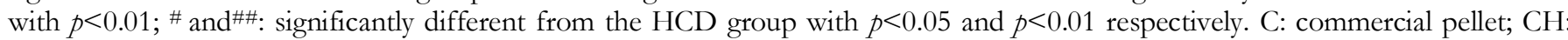
commercial pellet and $0.6 \mathrm{~g} / \mathrm{kg} /$ day Trihoney; HCD: $1 \%$ cholesterol diet; DH1: $1 \%$ cholesterol diet and $0.3 \mathrm{~g} / \mathrm{kg} / \mathrm{day}$ Trihoney; DH2: $1 \%$ cholesterol diet and $0.6 \mathrm{~g} / \mathrm{kg} /$ day Trihoney; DAt: $1 \%$ cholesterol diet and $2 \mathrm{mg} / \mathrm{kg} /$ day atorvastatin; TC: total cholesterol; LDLc: low-density lipoprotein cholesterol. 


\section{The effects of hypercholesterolemia, Trihoney and atorvastatin on testicular weight}

Table 3 demonstrates the effects of hypercholesterolemia, Trihoney and atorvastatin on the testicular weight. There was a reduction in the testicular weight of all treatment groups apart from the $\mathrm{CH}$ group which was comparable to the control $(p>0.05)$. The most prominent reduction was observed in DAt group, which showed a significantly lower absolute $(p<0.01)$ and relative weights $(p<0.01)$ of both testes compared to the control group. Administration of $1 \%$ cholesterol diet $(\mathrm{HCD})$ reduced the absolute $(p<0.01)$ and relative weights $(p<0.05)$ of both testes significantly compared to the control group. Likewise, there was a significant reduction in the absolute $(p<0.05)$ and relative weights $(p<0.05)$ of both testes in DH1 group compared to the control group. Although the testicular weights were higher in DH1 and DH2 than the HCD group, no significant difference was detected among these groups $(p>0.05)$. The increase in the weights of testes in $\mathrm{DH} 2$ group reached the level of no significant difference of $\mathrm{DH} 2$ from the control group neither in the absolute nor in the relative weights $(p>0.05)$. Trihoney received group (DH2) demonstrated significantly higher absolute $(p<0.01)$ and relative $(p<0.05)$ weights of the testes than the DAt group.

Table 3. The effects of hypercholesterolemia, Trihoney and atorvastatin on testicular weight.

\begin{tabular}{ccccc}
\hline $\begin{array}{c}\text { Organs } \\
\text { weight }\end{array}$ & $\begin{array}{c}\text { Absolute weight of } \\
\text { Rt. Testis } \\
\text { (g) }\end{array}$ & $\begin{array}{c}\text { Relative weight of } \\
\text { Rt. Testis } \\
\mathbf{( \% )}\end{array}$ & $\begin{array}{c}\text { Absolute weight of } \\
\text { Lt. testis } \\
\mathbf{( g )}\end{array}$ & $\begin{array}{c}\text { Relative weight of } \\
\text { Lt. testis } \\
\mathbf{( \% )}\end{array}$ \\
Groups & $2.13 \pm 0.23$ & $0.09 \pm 0.01$ & $2.10 \pm 0.33$ & $0.08 \pm 0.01$ \\
C & $1.95 \pm 0.30$ & $0.08 \pm 0.01$ & $1.85 \pm 0.22$ & $0.07 \pm 0.01$ \\
CH & $1.37 \pm 0.47^{* *}$ & $0.06 \pm 0.02^{*}$ & $1.39 \pm 0.47^{* *}$ & $0.06 \pm 0.02^{*}$ \\
HCD & $1.08 \pm 0.65^{* *}$ & $0.05 \pm 0.03^{* *}$ & $1.15 \pm 0.69^{* *}$ & $0.05 \pm 0.03^{* *}$ \\
DAt & $1.52 \pm 0.49^{*}$ & $0.06 \pm 0.02^{*}$ & $1.49 \pm 0.45^{*}$ & $0.06 \pm 0.02^{*}$ \\
DH1 & $1.84 \pm 0.34^{\#}$ & $0.07 \pm 0.02^{\#}$ & $1.75 \pm 0.37 \# \#$ & $0.07 \pm 0.02$ \\
DH2 & &
\end{tabular}

Data were analysed using one-way analysis of variance (ANOVA). A Post Hoc comparison using LSD test was used to test the significant difference between the groups. Values are given as mean \pm standard deviation. ${ }^{*}$ and ${ }^{* *}$ : significantly different from

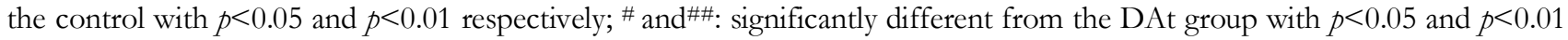
respectively. C: commercial pellet; $\mathrm{CH}$ : commercial pellet plus $0.6 \mathrm{~g} / \mathrm{kg} /$ day Trihoney; HCD: 1\% cholesterol diet; DH1: 1\% cholesterol diet plus $0.3 \mathrm{~g} / \mathrm{kg} /$ day Trihoney; DH2: $1 \%$ cholesterol diet plus $0.6 \mathrm{~g} / \mathrm{kg} / \mathrm{day}$ Trihoney; DAt: $1 \%$ cholesterol diet plus $2 \mathrm{mg} / \mathrm{kg} /$ day atorvastatin.

\section{The correlations of serum total cholesterol and low-density lipoprotein cholesterol with testicular weights}

Figures 1 and 2 illustrate the relationships between testicular weights and serum TC and LDL-c. A negative correlation was found between serum TC and the relative $(r=-0.527, p<0.01)$ and absolute $(r=-0.563, p<0.01)$ weights of right testis, and between serum TC and the relative $(r=-0.478, p<0.01)$ and absolute $(r=-0.517$, $p<0.01)$ weights of the left testis. Likewise, a negative correlation was observed between serum LDL-c and the relative $(r=-0.503, p<0.01)$ and absolute $(r=-0.538, p<0.01)$ weights of right testis, and between serum LDL-c and the relative $(r=-0.466, p<0.01)$ and absolute $(r=-0.490$, $p<0.01)$ weights of the left testis.

\section{The effects of hypercholesterolemia, Trihoney and atorvastatin on testicular gross morphology}

The testes of the control and $\mathrm{CH}$ groups were oval in shape, smooth in surface and plump in appearance with clear vascular texture. The testes of HCD and DAt groups were smaller in size and pale in colour when compared to the control. The appearance and size of testes of Trihoney received groups are almost similar to that of the control. 

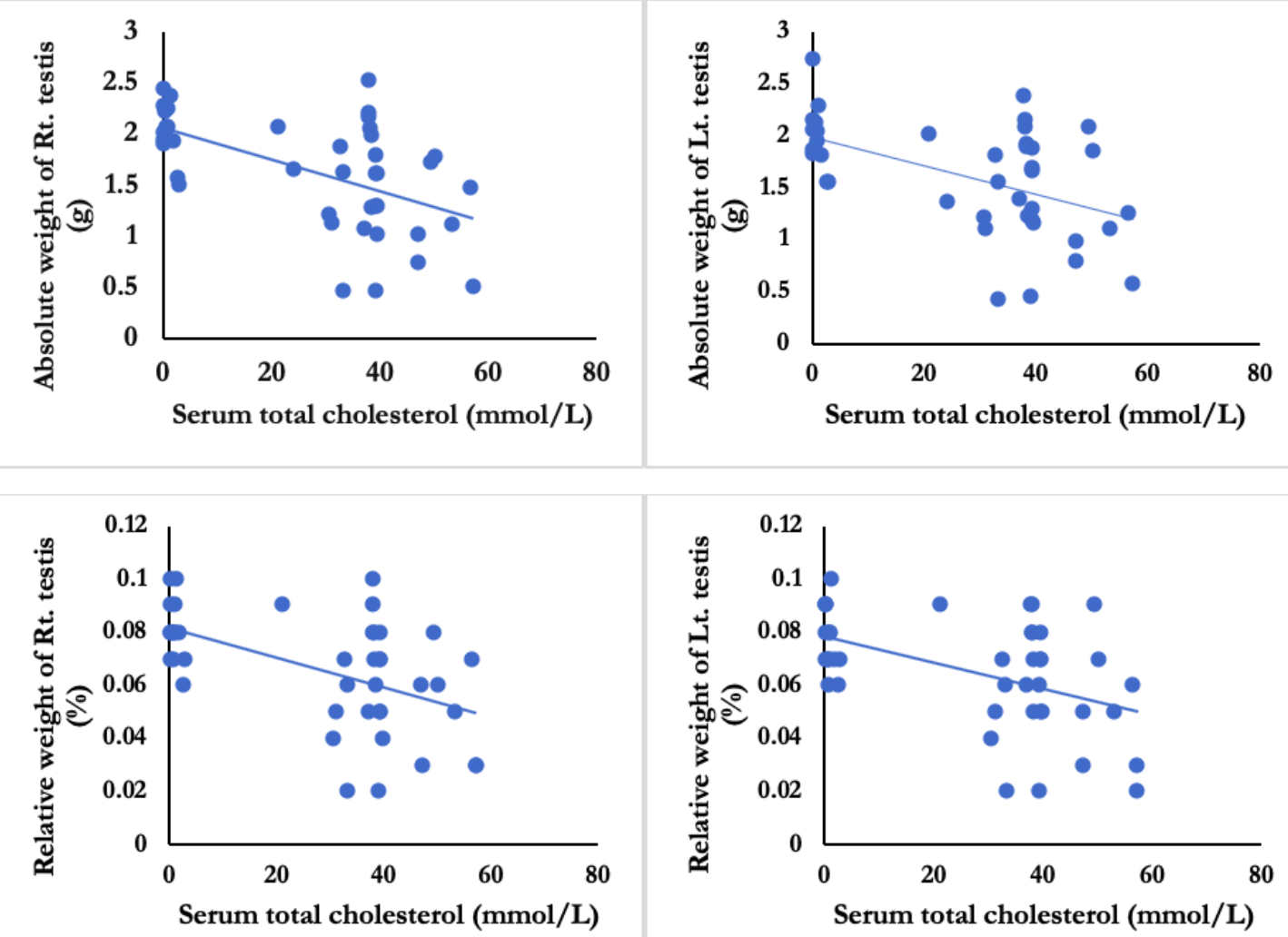

Figure 1. Correlations of serum total cholesterol with absolute and relative testicular weights. Rt: right; Lt: left. Total sample for correlation $(\mathrm{N})=42$.
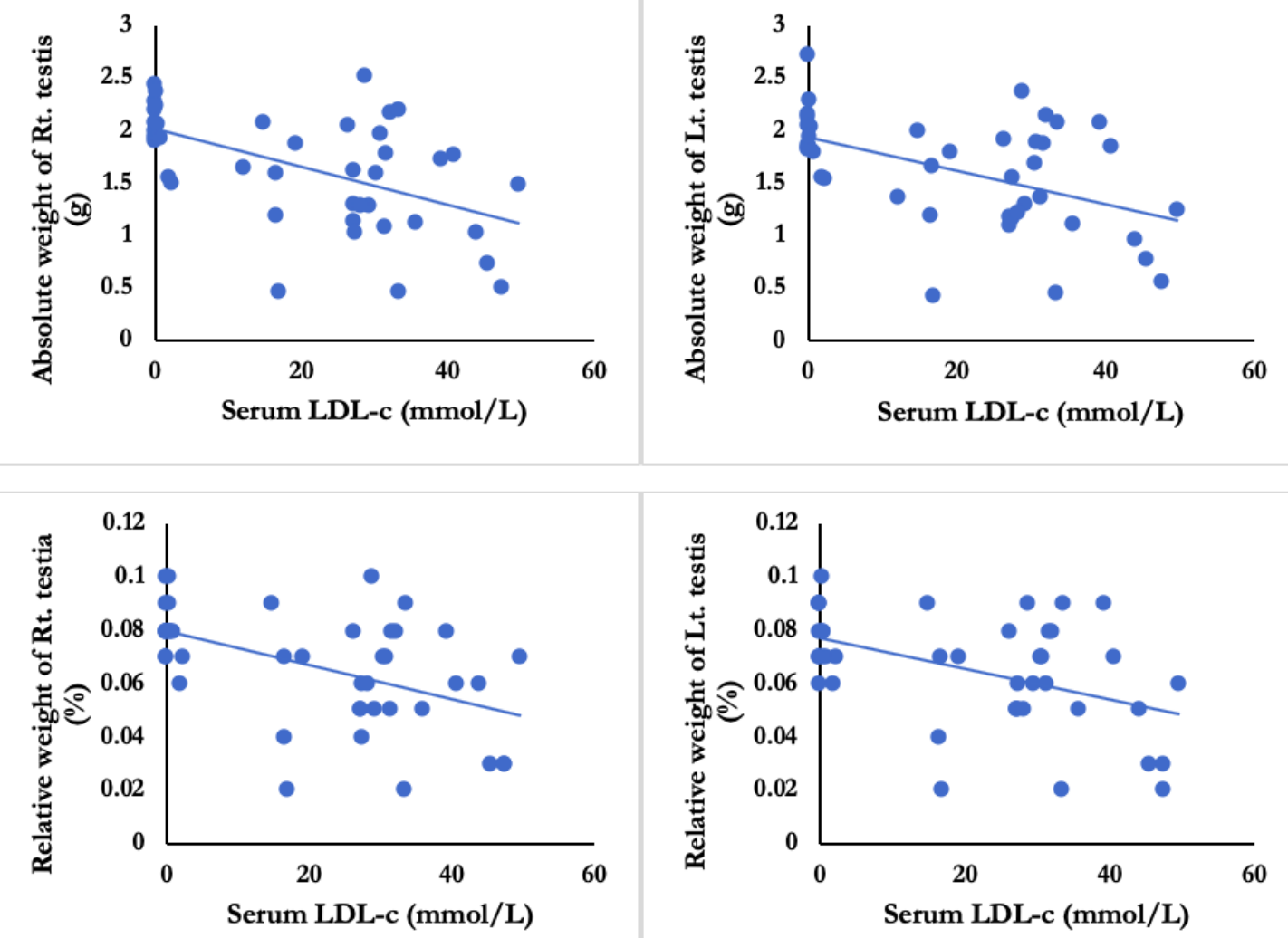

Figure 2. Correlations of serum LDL-c with absolute and relative testicular weights. Rt: right; Lt: left. Total sample for correlation $(\mathrm{N})=42$. 
The effects of hypercholesterolemia, Trihoney and atorvastatin on testicular histology

Whole sections of testes from all groups

Figure 3 illustrates testicular whole sections stained with H\&E from all of the experimental groups. They showed the increased thickness of tunica albuginea and the dilated congested blood vessels of HCD and DAt groups.

\section{Control groups}

Histopathological evaluation of testicular sections from the control and $\mathrm{CH}$ groups revealed normal testicular architecture (Figures 4 and 5).

\section{High cholesterol diet group}

The testicular sections from the HCD group exhibited some irregular seminiferous tubules with irregularity and thickening of their basement membrane, thickening of tunica albuginea, reduction of spermatogenic cells with wide areas of germ cell loss. disorganization of germ cells with exfoliated germ cells into tubular lumen and presence of multinucleated giant cells. There was a reduction in the thickness of germinal epithelium with some vacuolation. Sertoli cells revealed vacuolated cytoplasm. The interstitial spaces were wide and loaded with increased acidophilic hyaline material and congested blood vessels accompanied by Leydig cells hyperplasia (Figures 4 and 5).

\section{Atorvastatin treated group}

Histopathological analysis of the testicular sections from the DAt group revealed similar changes to that of the HCD group; however, the changes were more established in the DAt group. The nuclei of spermatogonia were dark and condensed; whereas, primary spermatocytes exhibited hyperchromatic nuclei. There was a loss of spermatids (Figures 4 and 5).

\section{Trihoney received groups}

The testicular sections from the DH1 group exhibited very few vacuolations in the germinal epithelium with an increase in spermatogenic cells layers at various stages of spermatogenesis. Some seminiferous tubular lumens were loaded with sperm. The interstitium was narrow and contained many Leydig cells. The histopathological improvements of the testicular tissue from the DH2 group were similar to that of the DH1 group; however, they were more marked in DH2 than DH1 (Figures 4 and 5).
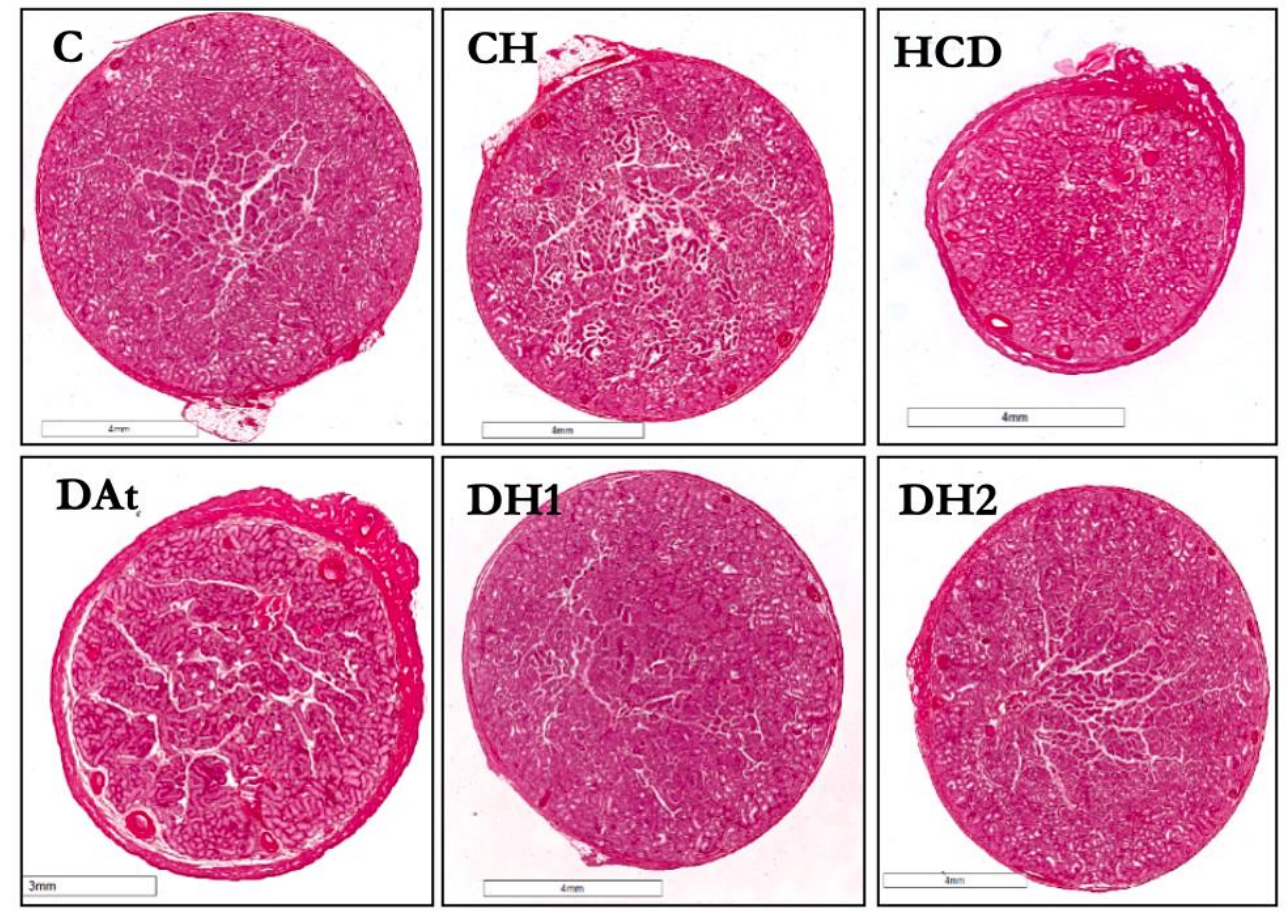

Figure 3. Pictomicrograph of testicular whole sections stained with Haematoxylin and Eosin (scale bar 4mm). C: commercial pellet; $\mathrm{CH}$ : commercial pellet with $0.6 \mathrm{~g} / \mathrm{kg} /$ day Trihoney; HCD: $1 \%$ cholesterol diet; DH1: $1 \%$ cholesterol diet with $0.3 \mathrm{~g} / \mathrm{kg} /$ day Trihoney; DH2: $1 \%$ cholesterol diet with $0.6 \mathrm{~g} / \mathrm{kg} / \mathrm{day}$ Trihoney; DAt: $1 \%$ cholesterol diet with $2 \mathrm{mg} / \mathrm{kg} /$ day atorvastatin. 

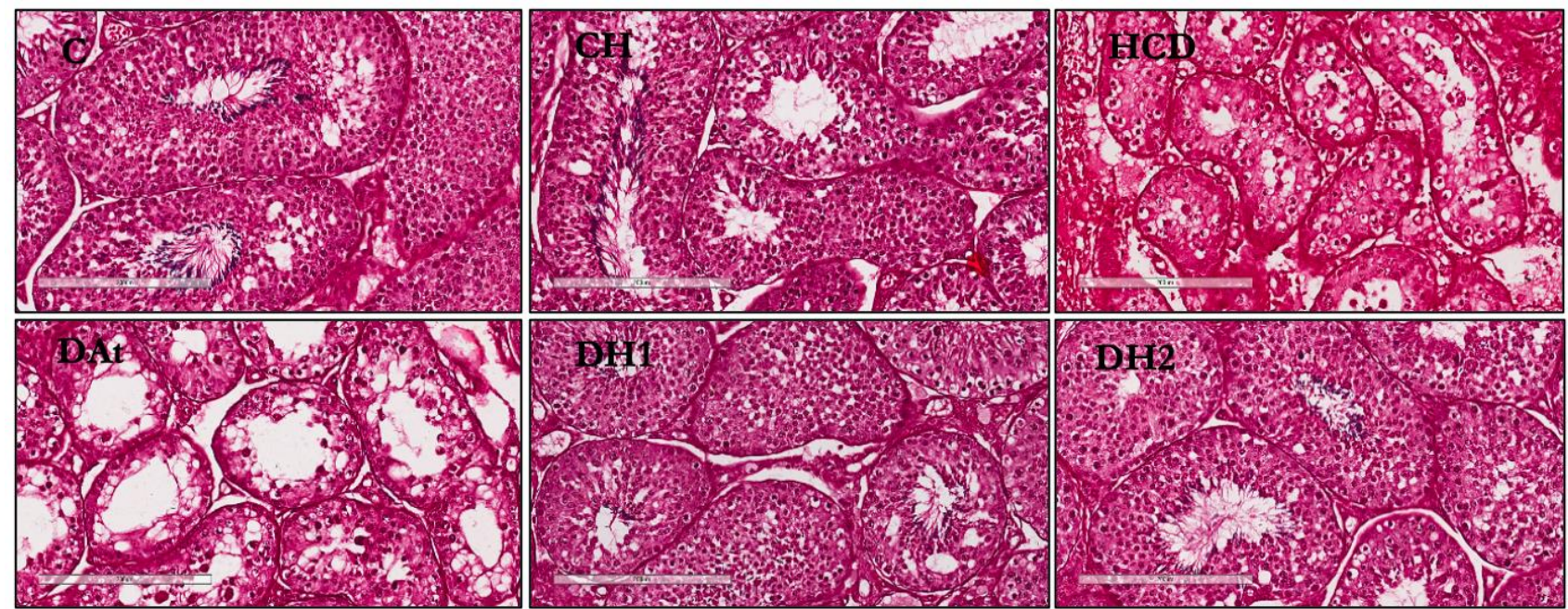

Figure 4. Pictomicrograph of testicular sections from the different groups stained with Haematoxylin and Eosin (scale bar $200 \mu \mathrm{m}$ ). C: commercial pellet; $\mathrm{CH}$ : commercial pellet with $0.6 \mathrm{~g} / \mathrm{kg} / \mathrm{day}$ of Trihoney; HCD: $1 \%$ cholesterol diet; DAt: 1\% cholesterol diet with $2 \mathrm{mg} / \mathrm{kg} /$ day of atorvastatin; DH1: $1 \%$ cholesterol diet with $0.3 \mathrm{~g} / \mathrm{kg} /$ day of Trihoney; DH2: $1 \%$ cholesterol diet with $0.6 \mathrm{~g} / \mathrm{kg} / \mathrm{day}$ of Trihoney.
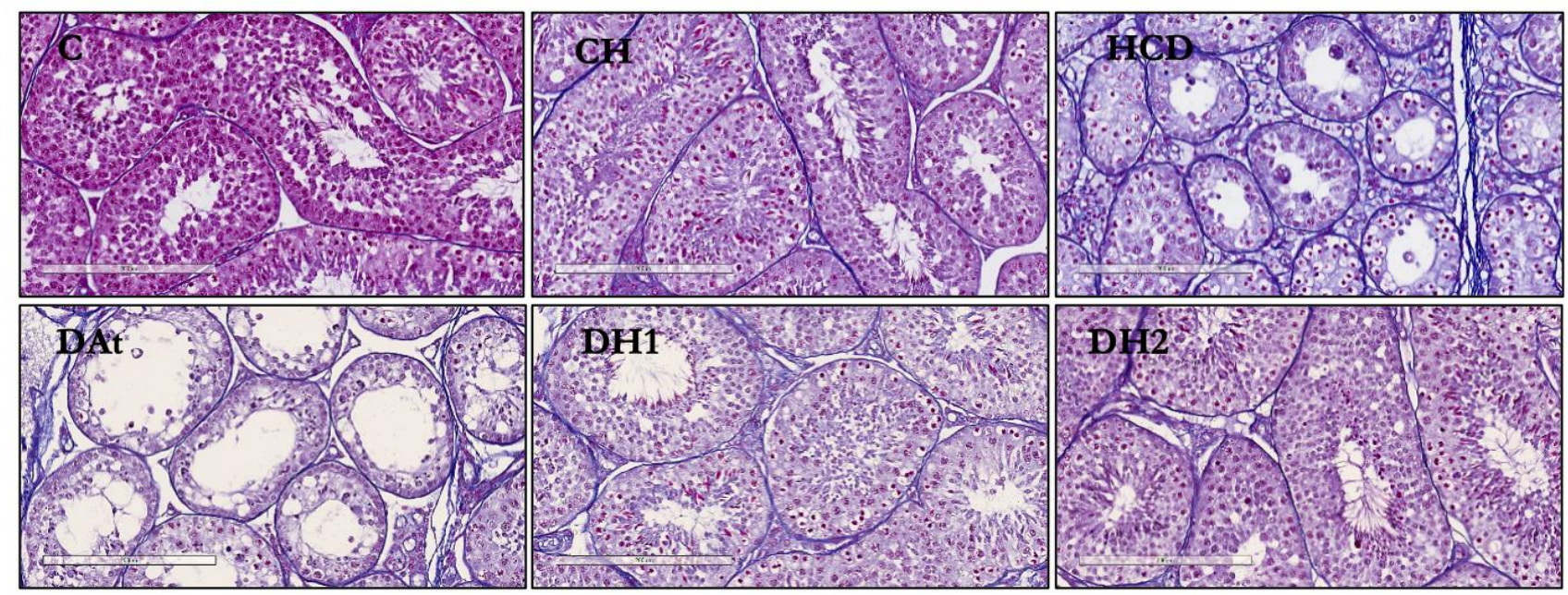

Figure 5. Pictomicrograph of testicular sections from the different groups stained with Masson's Trichrome stain (scale bar $200 \mu \mathrm{m})$. C: commercial pellet; $\mathrm{CH}$ : commercial pellet with $0.6 \mathrm{~g} / \mathrm{kg} / \mathrm{day}$ of Trihoney; HCD: 1\% cholesterol diet; DAt: 1\% cholesterol diet with $2 \mathrm{mg} / \mathrm{kg} /$ day of atorvastatin; DH1: $1 \%$ cholesterol diet with $0.3 \mathrm{~g} / \mathrm{kg} /$ day of Trihoney; DH2: $1 \%$ cholesterol diet with $0.6 \mathrm{~g} / \mathrm{kg} / \mathrm{day}$ of Trihoney.

\section{The effects of hypercholesterolemia, Trihoney and atorvastatin on the diameter of seminiferous tubules, the thickness of tunica albuginea and Johnsen's score}

The effects of $1 \%$ cholesterol diet, Trihoney and atorvastatin on the diameter of seminiferous tubules, the thickness of tunica albuginea and Johnsen's score are described in Table 4. In comparison to the control group, HCD, DAt, DH1 and DH2 exhibited a significant reduction of seminiferous tubules diameter $(p<0.01)$ and a significant reduction of Johnsen's score $(p<0.01)$.
Trihoney received groups (DH1 and DH2) showed a significant increase in the diameter of the seminiferous tubules $(p<0.01)$ and a significant increase in Johnsen's score $(p<0.01)$ compared to HCD and DAt groups. Although DH2 showed a larger seminiferous tubules diameter and higher Johnsen's score than DH1, no significant difference was observed between these two groups $(p>0.05)$. Atorvastatin received group demonstrated smaller seminiferous tubules diameter than HCD group with no significant difference found $(p>0.05)$. However, the DAt 
group showed a significantly lower Johnsen's score than HCD group $(p<0.01)$. With regards to the thickness of tunica albuginea, the HCD and DAt groups expressed a significantly thicker tunica albuginea than the control group $(p<0.01)$. The group of rabbits that received Trihoney at the dose of $0.3 \mathrm{~g} / \mathrm{kg} /$ day (DH1) demonstrated a significant increase in the thickness of tunica albuginea compared to the control group $(\phi<0.01)$; meanwhile, it demonstrated a significant reduction in the thickness compared to HCD and DAt groups $(p<0.01)$. The DH2 exhibited no significant difference from the control in the thickness of tunica albuginea ( $p>0.05)$; meanwhile, it was significantly lower than HCD and DAt groups $(p<0.01)$. No significant difference was detected between DH1 and DH2 in the thickness of tunica albuginea $(p>0.05)$.

Table 4. The effects of 1\% cholesterol diet, Trihoney and atorvastatin on seminiferous tubules diameter, tunica albuginea thickness and Johnsen's score.

\begin{tabular}{cccc}
\hline Parameters & $\begin{array}{c}\text { Seminiferous tubules } \\
\text { diameter } \\
(\mu \mathrm{m})\end{array}$ & $\begin{array}{c}\text { Thickness of tunica } \\
\text { albuginea }(\mu \mathrm{m})\end{array}$ & Johnsen’s score \\
Groups & $202.80 \pm 24.85$ & $64.55 \pm 9.08$ & $9.78 \pm 0.42$ \\
C & $201.87 \pm 21.59$ & $67.51 \pm 15.96$ & $9.75 \pm 0.44$ \\
CH & $155.55 \pm 14.58^{* *}$ & $198.27 \pm 24.18^{* *}$ & $5.45 \pm 0.50^{* *}$ \\
HCD & $149.53 \pm 19.22^{* *}$ & $78.95 \pm 26.67^{* *}$ & $4.20 \pm 0.40^{* *, \# \#}$ \\
DAt & $176.29 \pm 25.54^{* *, \# \#, \wedge}$ & $95.72 \pm 15.83^{* *, \# \#, \wedge \wedge}$ & $7.20 \pm 0.66^{* *, \# \#, \wedge \wedge}$ \\
DH1 & $181.66 \pm 18.62^{* *, \# \#, \wedge^{\wedge}}$ & $75.10 \pm 11.72^{\# \#, \wedge \wedge}$ & $8.05 \pm 0.67^{* *, \# \#, \wedge \wedge}$ \\
DH2 &
\end{tabular}

Data were analysed using one-way analysis of variance (ANOVA). A Post Hoc comparison using Tukey HSD test was used to test the significant difference between the groups. Values are given as mean \pm standard deviation. ${ }^{* *}$ : significantly different from the control with $p<0.01$; \#\#: significantly different from the HCD group with $p<0.01$; $^{\wedge}$ : significantly different from the DAt group with $p<0.01$. C: commercial pellet; $\mathrm{CH}$ : commercial pellet plus $0.6 \mathrm{~g} / \mathrm{kg} /$ day Trihoney; HCD: $1 \%$ cholesterol diet; DH1: $1 \%$ cholesterol diet plus $0.3 \mathrm{~g} / \mathrm{kg} /$ day Trihoney; DH2: $1 \%$ cholesterol diet plus $0.6 \mathrm{~g} / \mathrm{kg} /$ day Trihoney; DAt: $1 \%$ cholesterol diet plus $2 \mathrm{mg} / \mathrm{kg} /$ day atorvastatin.

\section{DISCUSSION}

The observed changes of lipid profile in the current study confirmed the development of hypercholesterolemia through the administration of $1 \%$ cholesterol diet. This was indicated by the elevation of serum total cholesterol and LDL-c in the treatment groups. Trihoney supplementation and atorvastatin treatment resulted in an improvement of hypercholesterolemia evidenced by a significant reduction in the serum TC and LDL-c. Trihoney was as effective as atorvastatin in the lipid lowering effect.

Feeding of rabbits with $1 \%$ cholesterol diet caused a significant reduction in the relative and absolute testicular weights. In line with these results, Alzubaidi \& Diwan (2013) and Shalaby (2004) reported that there was a reduction in the relative testicular weight of rats fed with $1.5 \%$ cholesterol diet and rats fed with $1 \%$ cholesterol diet respectively. However, Yamamoto et al. (1999) reported that feeding of rabbits with 3\% cholesterol diet had no impact on the absolute weight of the testes. In the current study, a negative correlation was shown between serum TC and LDL-c and testicular weights. Inconsistent results were observed by Louei Monfared (2013) who reported that no correlation was found between serum TC and LDL-c and testicular weight.

Treatment of the rabbits with atorvastatin in this study reduced the absolute and relative testicular weights more than any other group. The negative impact of atorvastatin on the relative and absolute testicular weights was reported previously in rat and mice models (Bustan \& Jawad, 2017; Niederberger, 2005). The primary causes of testicular weight reduction are; 1) germ cell depletion, which could be due to the 
disruption of spermatogenesis through the effects on germ cells, Sertoli cells, blood supply or hormonal disturbances; 2) seminiferous tubules lumen contraction, which is caused by reduced production of seminiferous tubule fluid that may be resulted from the loss of elongated spermatids and/or the reduction in testosterone production (Creasy \& Chapin, 2013). Disruption of spermatogenesis with reduction of sperm production that cause testicular weight reduction is one of the main causes of epididymal weight reduction (Creasy \& Chapin, 2013). Our previously published study demonstrated that atorvastatin showed no improvement in the relative epididymal weight of hypercholesterolemic rabbits; meanwhile, it caused a worse reduction in the absolute epididymal weight than the administration of high cholesterol diet alone (Mohamed et al., 2020).

The reduction of testicular weight was improved by administration of Trihoney at the dose of $0.3 \mathrm{~g} / \mathrm{kg} /$ day and was reversed by the dose of $0.6 \mathrm{~g} / \mathrm{kg} /$ day. These findings were supported by numerous studies in which administration of different types of honey to normal and diabetic rats exhibited no negative impact on the testicular weights (Michael et al., 2015; Mohamed et al., 2012; Syazana et al., 2011). Moreover, Oyelowo et al. (2014) reported that honey supplementation to rats increased testicular weight significantly. The improvement of testicular weight via Trihoney administration could be through the enhancement of spermiogenesis and spermatogenesis by maintaining testicular integrity and optimizing neuroendocrine gonadal axis with an elevation of testosterone hormone and a subsequent improvement in spermatogenesis as shown previously with other types of honey (AbdulGhani et al., 2008; Kenani et al., 2015; Michael et al., 2015; Mohamed et al., 2012). It could also be through the hypocholesterolemic effect of Trihoney that may improve testicular weight as there was a negative correlation between testicular weights and lipid profile (Figures 1 and 2).

Histologically, the current study demonstrated that hypercholesterolemic rabbits showed significant testicular tubular degenerative changes and impaired spermatogenesis. According to Creasy et al., (2012), degenerative changes of testicular tubules are diagnosed based on the presence of any combination of degeneration of germ cell, retention of spermatid, vacuolation of Sertoli cell cytoplasm, disorganization of germ cells, exfoliation of germ cells into tubular lumen, germ cell loss, multinucleated germ cells, and degenerated germ cells and debris in the epididymis. These changes are usually associated with reduced testicular weight. Germ cells degeneration, depletion or disorganization are the most common manifestation of toxicological injury to the testes. The impact of the toxicants on germ cells can be induced through Sertoli cells via the disruption of pathways that regulate or supply energy to germ cells, or through an effect on Leydig cells to decrease testosterone production. It could also be through anoxia due to an effect on the vasculature (Creasy \& Chapin, 2013). Another common manifestation of testicular toxicants exposure is tubular degeneration which mediated through Sertoli cell injury, germ cell injury, hormonal disruption, or vascular effects (Creasy et al., 2012). The presence of irregular thickened basement membrane of seminiferous tubules would cause a reduction of sperm production as the basement membrane has an important role in spermatogenesis (Zhang et al., 2012). Leydig cells hyperplasia is a physiological response to endocrine disruption. It occurs in response to increased level of luteinizing hormone from the anterior pituitary gland or release of stimulatory factors within the testicular tissue. Leydig cells hyperplasia accompanies severe degenerative changes of seminiferous tubules and reduced spermatogenesis (Creasy \& Chapin, 2013).

The histopathological findings of the present study are supported by a former study by Ashrafi et al. (2013), which reported that feeding of New Zealand rabbits with a cholesterol enriched diet for 12 weeks resulted in disorganization and reduced thickness of the germinal epithelium, increased inter-tubular connective tissue, vasodilatation of the blood vessels in the interstitial tissue and a significant reduction in Johnsen's score. In another study conducted by Shalaby (2004), feeding of rats with $1 \%$ cholesterol diet for 65 days resulted in degenerative changes in the seminiferous tubules with spermatogenesis impairment in most of the testicular tissue. Histopathological examination of ApoE deficient mice fed with a diet enriched with 
$0.5 \%$ cholesterol for 12 weeks induced reduction of spermatogenesis, disruption of seminiferous tubules with an irregularity and thickening of their basement membrane. Furthermore, there was damage to the ultrastructure of Sertoli and Leydig cells and a significant reduction in Johnsen's score of those mice (Zhang et al., 2012). Administration of cholesterol at a dose of $400 \mathrm{mg} / \mathrm{kg} /$ day to rats for 2 months resulted in shrunken irregular seminiferous tubules, reduction in the diameter of seminiferous tubules, reduction of spermatocytes and spermatids, spermatogenesis arrest and enlarged interstitium. Leydig cells demonstrated shrunken nuclei and reduced Leydig cell nuclear diameters; whereas, the number of degenerated Leydig cells increased (Bataineh \& Nusier, 2005; Purohit \& Daradka, 1999). Although the main mechanism through which hypercholesterolemia induces testicular damage is still obscure, particular attention has been paid to the cytotoxic effects of ROS and oxidative stress on the testicular tissue and spermatogenesis (Shalaby, 2004; Samir Bashandy, 2007; Ediz \& Altintas, 2014).

The treatment of rabbits with atorvastatin in the present study induced more severe testicular tubular degenerative changes than using high cholesterol diet alone. These changes together with the worst outcome of atorvastatin on the testicular and epididymal weights may indicate that the testicular tissue of animals from this group was exposed to more toxic effects which might be due to atorvastatin itself. These findings are further supported by the recently published effects of atorvastatin on epididymal histology. It has been shown that atorvastatin treatment of high cholesterol diet-fed male rabbits associated with epididymal atrophy and reduced number of mature sperm with a moderate increase in the cellular debris in epididymal tubules (Mohamed et al., 2020). These epididymal histopathological changes are a common association with severe testicular tubular degeneration (Creasy at al., 2012). In line with this study, treatment of mice with atorvastatin for 21 days resulted in the disruption of normal testicular histology in the form of thickening of seminiferous tubules wall, widening of inter-tubular space, vacuolation of Sertoli cells, intercellular vacuolation and sloughed germinal epithelium (Bustan \& Jawad, 2017). In rats, treatment with atorvastatin caused oedema of the testicular interstitial tissue (Das \& Indira, 2015). In a case report study, atorvastatin was one among three statins that induced testicular pain. Urologic adverse effects of statins rarely occur but should not be neglected (Linnebur \& Hiatt, 2007).

Concurrent supplementation of Trihoney with high cholesterol diet particularly at the dose of $0.6 \mathrm{~g} / \mathrm{kg} /$ day ameliorated the degenerative changes of the testicular tissue and improved spermatogenesis. To the best of our knowledge, this is the first study that attempted to investigate the protective effects of honey against testicular histopathological changes induced by hypercholesterolemia. Several studies have been undertaken to determine the importance of honey in attenuating the impacts of other toxicants on the testicular histology. Furthermore, honey has been used in different cultures to enhance male fertility. Administration of honey-based diet to normal and diabetic rats revealed densely packed spermatogenic cells in the seminiferous tubular lumen with numerous sperm tails in comparison to the normal diet-fed rats, which showed sparsely packed spermatogenic cells with few sperm tails (Syazana et al., 2011; Michael et al., 2015). Supplementation of honey to cigarette smokeexposed rats significantly reduced testicular degenerative changes induced by the toxic effects of cigar-smoke on the testicular structure. This protective effect of honey was suggested to be due to its antioxidant properties (Mohamed et al., 2011). Moreover, honey was found to have a positive influence on testicular parenchyma through combating apoptosis and necrosis of testicular cells, which is likely due to the antioxidant properties of honey (Saki et al., 2013). Honey also exhibited its ability to maintain testicular integrity and optimize neuroendocrine gonadal axis, which, in turn, augments spermatogenesis that may be due to its antioxidant activities (Kenani et al., 2015). These mechanisms are the most likely underlying mechanisms through which Trihoney with its high total phenolic content (TPC) and antioxidant activity improved the testicular histopathological changes and spermatogenesis with a subsequent improvement of testicular weight in this study. The improvements of testicular histopathology and spermatogenesis are the main mechanisms that drive the improvements in the epididymal 
weight and histopathology in our previously published study (Mohamed et al., 2020).

\section{CONCLUSION}

Trihoney plays a favourable role in the protection against testicular weight reduction and histopathological changes induced by hypercholesterolemia in the rabbit model. On the other hand, atorvastatin treatment induced more severe testicular degenerative changes than using high cholesterol diet alone, which may indicate the toxic effect of atorvastatin on the testicular tissue. The protective effects of Trihoney are likely due to its lipid-lowering and antioxidant characteristics that need to be evaluated in future studies. Moreover, further works are needed to investigate the adverse effects of atorvastatin on the male reproductive system, particularly in young adults who wish to father children.

\section{ACKNOWLEDGEMENTS}

The authors gratefully acknowledge the kind cooperation of all staff in the Central Research and Animal Facility (CREAM), International Islamic University Malaysia and Department of Basic Medical Sciences, Kulliyyah of Pharmacy, International Islamic University Malaysia and Department of Pathology \& Laboratory Medicine, International Islamic University Malaysia Medical Centre for the services and facilities provided.

\section{REFERENCES}

Abdul-Ghani, A-S., Dabdoub, N., Muhammad, R., Abdul-Ghani, R., \& Qazzaz, M. 2008. Effect of Palestinian honey on spermatogenesis in rats. Journal of Medicinal Food 11(4): 799802.

Al-Kushi, A., El Sawy, N. A., Hijazi, M. M., \& Hataba, A. A. 2016. Therapeutic effect of vitamin $\mathrm{E}$ on testicular tissue damage caused by obesity. Journal of Obesity \& Weight Loss Therapy 06(05): $1-5$

Alzubaidi, N. A. K., \& Diwan, M. A. A. 2013. The effect of taurine on reproductive efficiency in male rats fed high cholesterol diet. Basrah Journal of Veterinary Research 12(1): 30-40.

Ashrafi, H., Ghabili, K., Alihemmati, A., Jouyban, A., Shoja, M.,
Aslanabadi, S., \& Hajhosseini, L. 2013. The effect of quince leaf (Cydonia oblonga miller) decoction on testes in hypercholesterolemic rabbits: A pilot study. African Journal of Traditional, Complementary and Alternative Medicines 10(2): 277-282.

Bataineh, H. N., \& Nusier, M. K. 2005. Effect of cholesterol diet on reproductive function in male albino rats. Saudi Medical Journal 26(3): 398-404.

Bõsze, Z., \& Houdebine, L. M. 2006. Application of rabbits in biomedical research: A review. World Rabbit Science 14(1): 114.

Bustan, A., \& Jawad, A. 2017. The effect of two types of statins (rosuvastatin and atorvastatin) on the fertility of male and female mice. British Journal of Medicine and Medical Research 19(12): 1-11.

Creasy, D., Bube, A., Rijk, E. de, Kandori, H., Kuwahara, M., Masson, R., \& Whitney, K. 2012. Proliferative and nonproliferative lesions of the rat and mouse male reproductive system. Toxicologic Pathology 40(6S): 40S-121S.

Creasy, D., Cartwright, J., Moreland, S., Willoughby, C., Collier, M., \& Odum, J. 2008. Endocrine disruption: a guidance document for histologic evaluation of endocrine and reproductive tests.

Creasy, D. M. 2001. Pathogenesis of male reproductive toxicity. Toxicologic Pathology 29(1): 64-76.

Creasy, D. M., \& Chapin, R. E. 2013. Male reproductive system. In Haschek and Rousseaux's Handbook of Toxicologic Pathology (Third edit, pp. 2493-2598). USA: Elsevier Inc., Academic Press.

Das, S., \& Indira, M. 2015. Combined effects of atorvastatin and nicotine on testicular expression of steriodogenic enzymes in experimental rats. International Journal of Pharmaceutical Sciences and Research 6(6): 2511-2517.

Dohle, G. R., Elzanaty, S., \& van Casteren, N. J. 2012. Testicular biopsy: clinical practice and interpretation. Asian Journal of Andrology 14(1): 88-93.

Du, B., Xu, G., Cao, H., Cui, W., Lin, S., Liu, Y., \& Qin, L. 2013. Effects of atorvastatin on expression of ICAM-1 in atherosclerotic rabbits. Journal of Cardiovascular Medicine 14(2): 120-126.

Ediz, C., \& Altintas, R. 2014. The metabolic syndrome and male infertility: a review of the literature. Diabetes \& Metabolic Disorders 1(1): 1-4.

Erdemir, F., Atilgan, D., Markoc, F., Boztepe, O., Suha-Parlaktas, B., \& Sahin, S. 2012. The effect of diet induced obesity on testicular tissue and serum oxidative stress parameters. Actas Urológicas Españolas (English Edition) 36(3): 153-159.

Fan, J., Kitajima, S., Watanabe, T., Xu, J., Zhang, J., Liu, E., \& Chen, Y. E. 2016. Rabbit models for the study of human atherosclerosis: from pathophysiological mechanisms to translational medicine. Pharmacology and Therapeautics 21(2): $1-38$.

Foote, R. H., \& Carney, E. W. 2000. The rabbit as a model for reproductive and developmental toxicity studies. Reproductive Toxicology 14(6): 477-493.

Galaly, S. R., Hozayen, W. G., Amin, K. A., \& Ramadan, S. M. 2014. Effects of orlistat and herbal mixture extract on brain, testes functions and oxidative stress biomarkers in a rat model of high fat diet. Beni-Suef University Journal of Basic and Applied Sciences 3(2): 93-105.

Jasiñska, M., Owczarek, J., \& Orszulak-Michalak, D. 2007. Statins: a new insight into their mechanisms of action and consequent pleiotropic effects. American Journal of Epidemiology 59(9): 483-499.

Kenani, M., Rajabzadeh, A., Saki, G., Khodadadi, A., Sarkaki, A., Jafai, A., \& Hemadi, M. 2015. A survey of the relationship between noised pollution, honey and vitamin $\mathrm{E}$ and plasma level of blood sexual hormones in noise-exposed rats. Jentashapir Journal of Health Research 6(1): 1-5. 
Leary, S., Underwood, W., Anthony, R., Cartner, S., Corey, D., Grandin, T., Patterson-kane, E. 2013. AVMA Guidelines for the Euthanasia of Animals (2013 Editi). Schaumburg: American Veterinary Medical Association.

Linnebur, S. A., \& Hiatt, W. H. 2007. Probable statin-induced testicular pain. The Annals of Pharmacotherapy 41(1): 138-142.

Louei Monfared, A. 2013. Correlation of serum lipid profile with histological and seminal parameters of testis in the goat. International Journal of Fertility and Sterility 7(2): 122-129.

Michael, M., Anyakudo, C., Balogun, A. J., \& Adeniyi, M. O. 2015. Beneficial effects of honey-based diet on glycemic control and reproductive potential in diabetic rats. World Journal of Nutrition and Health 3(2): 41-46.

Mohamed, M., Sulaiman, S. A., Jaafar, H., \& Sirajudeen, K. N. S. 2012. Effect of different doses of Malaysian honey on reproductive parameters in adult male rats. Andrologia 44: 182-186.

Mohamed, Mahaneem, Sulaiman, S. A., Jaafar, H., \& Sirajudeen, K. N. S. 2011. Antioxidant protective effect of honey in cigarette smoke-induced testicular damage in rats. International Journal of Molecular Sciences 12(9): 5508-5521.

Mohamed, Z. B. H., Ibrahim, M. Bin, Alfarisi, H. A. H., Abdul Wahab, A. Y., Abd Fuaat, A., \& Mohamad, C. A. C. 2020. Trihoney ameliorates hypercholesterolemia-induced epididymal histopathological changes in male rabbits. Asia Pacific Journal of Molecular Biology and Biotechnology 28(1): 90100.

Niederberger, C. 2005. Atorvastatin and male infertility : is there a link? Journal of Andrology 26(1): 12.

Oyelowo, O. T., Adekunbi, D. A., \& Dada, K. A. 2014. Protective role of Nigerian honey on sperm indices and testis in sucrose-fed rats. Bangladesh Journal of Medical Science 13(2): 180-189.

Pons-Rejraji, H., Brugnon, F., Sion, B., Maqdasy, S., Gouby, G., Pereira, B., \& Tauveron, I. 2014. Evaluation of atorvastatin efficacy and toxicity on spermatozoa, accessory glands and gonadal hormones of healthy men: a pilot prospective clinical trial. Reproductive Biology and Endocrinology 12(1): 65.

Purohit, A., \& Daradka, H. M. M. 1999. Effect of mild hyperlipidaemia on testicular cell population dynamics in albino rats. Indian Journal of Experimental Biology 37(4): 396398.

Reagan-Shaw, S., Nihal, M., \& Ahmad, N. 2007. Dose translation from animal to human studies revisited. The FASEB Journal, 22(3): 659-661.

Saki, G., Sarkaki, A., Hemadi, M., Khodadadi, A., \& Rajabzadeh, A. 2013. The effects of honey and vitamin $\mathrm{E}$ administration on apoptosis in testes of rat exposed to noise stress. Journal of Human Reproductive Sciences 6(1): 54-58.

Samir Bashandy, A. . 2007. Effect of fixed oil of Nigella sativa on male fertility in normal and hyperlipidemic rats. International Journal of Pharmacology 3(1): 27-33.

Shalaby, M. 2004. Effect of alpha-tocopherol and simvastatin on male fertility in hypercholesterolemic rats. Pharmacological Research 50(2): 137-142.

Sherwood, L. 2010. Human Physiology From Cells to Systems (seventh ed). Brooks/Cole. USA.

Song, X., Liu, H., Wang, X., Li, Z., \& Huang, C. 2014. Atorvastatin combined with poly-unsaturated fatty acid confers better improvement of dyslipidemia and endothelium function. Lipids in Health and Disease 13(186): 1-5.

Syazana, N. S., Hashida, N. H., Majid, A. M., Durriyyah Sharifah, H. A., \& Kamaruddin, M. Y. 2011. Effects of Gelam honey on sperm quality and testis of rat. Sains Malaysiana 40(11): 1243-1246.

Vidal, J. D., \& Whitney, K. M. 2014. Morphologic manifestations of testicular and epididymal toxicity. Spermatogenesis 4(2): 117.
Whitfield, M., Pollet-Villard, X., Levy, R., Drevet, J. R., \& Saez, F. 2015. Post-testicular sperm maturation, infertility and hypercholesterolaemia. Asian Journal of Andrology 17: 742748.

Yamamoto, Y., Shimamoto, K., Sofikitis, N., \& Miyagawa, I. 1999. Effects of hypercholesterolaemia on Leydig and Sertoli cell secretory function and the overall sperm fertilizing capacity in the rabbit. Human Reproduction 14(6): 1516-1521.

Zhang, K., L., Z., Jia, X., \& Huang, D. 2012. Melatonin prevents testicular damage in hyperlipidaemic mice. Andrologia 44(4): 230-236.

Zhao, X.-H., Qiu, J.-H., Cai, W.-Q., Li, S., \& Li, W. 2013. Preparation of infertile male rabbits by local electron beam irradiation for intratesticular transplantation of autologous bone marrow stem cells. Acta Cirurgica Brasileira 28(2): 148153. 